\title{
The Relationship Between Health Outcomes and Health Expenditure in Europe by Using Compositional Data Analysis
}

\section{Związek między stanem zdrowia a wydatkami na zdrowie w krajach Europy, w oparciu o analizę danych złożonych}

\author{
Magdaléna Drastichová*, Peter Filzmoser** \\ *Technical University of Ostrava, Czech Republic \\ E-mail: magdalena.drastichova@vsb.cz \\ **Vienna University of Technology, Austria \\ E-mail: peter.filzmoser@tuwien.ac.at
}

\begin{abstract}
The type of health system in each country and the resources devoted to it determine its outcomes. Relationships between ratios of expenditure to Gross Domestic Product (GDP) classified by provider and indicators reflecting health outcomes in 2015 are examined for 30 countries by means of a compositional data analysis and a regression analysis. The countries in the sample are the European Union (EU-28) countries plus Iceland and Norway. The outcome indicators used are life expectancy at birth (LE); healthy life years in absolute value at birth for females (HLYf) and for males (HLYm); and death rate due to chronic diseases (DR) (response variables). The results indicate that the higher the ratio of expenditure on retailers and other providers of medical goods in relation to other types of expenditure in the composition, the higher the DR indicator and the lower the LE indicator. The ratio of expenditure on residential long-term care facilities in the composition seems to have had a positive effect on both HLY indicators. The effect of expenditure ratios on providers of healthcare system administration and financing is not straightforward.
\end{abstract}

Key words: healthcare expenditure, life expectancy, healthy life years, death rate due to chronic diseases, sustainability, efficiency, compositional data analysis

\section{Streszczenie}

Rodzaj systemu opieki zdrowotnej w każdym kraju i środki na niego przeznaczone determinują jego skuteczność. W tej pracy zbadano zależności między stosunkami wydatków do produktu krajowego brutto (PKB), a wskaźnikami odzwierciedlającymi wyniki zdrowotne w 2015 r. w 30 krajach za pomocą analizy danych złożonych (CoDA) i analizy regresji. To kraje Unii Europejskiej (UE-28) oraz Islandia i Norwegia. Stosowanymi wskaźnikami wyników są: oczekiwana długość życia w chwili urodzenia (LE); lata zdrowego życia w wartości bezwzględnej przy urodzeniu dla kobiet (HLYf) i dla mężczyzn (HLYm); oraz wskaźnik zgonów z powodu chorób przewlekłych (DR). Wyniki wskazują, że im wyższy stosunek wydatków na zdrowie w stosunku do innych rodzajów wydatków, tym wyższy wskaźnik DR i niższy wskaźnik LE. Stosunek wydatków na placówki długoterminowej opieki zdrowotnej miał pozytywny wpływ na oba wskaźniki HLY. Natomiast wpływ wskaźników wydatków na zarządców systemu opieki zdrowotnej i jego finansowania nie jest jednoznaczny.

Słowa kluczowe: wydatki na zdrowie, długość życia, czas życia w zdrowiu, śmiertelność w wyniku chorób przewlekłych, zrównoważoność, wydajność, analiza danych złożonych 


\section{Introduction}

The rationale behind this work lies in a consideration of the concept of sustainable development (SD) and its adoption as a basic philosophy. Since its essential definition was accepted (WCED, 1987), many further definitions, methods of measurement, and parameters have been developed. According to this definition (WCED, 1987), SD is development that meets the needs of the present without compromising the ability of future generations to meet their own needs. The three-pillar approach to SD is based on that view of SD which refers simultaneously to economic, social and environmental systems, all of which must be sustainable at the same time. This is because each of these pillars is independently crucial and the pillars are interlinked. Moreover, the fourth, institutional dimension is emphasized as the fourth pillar of SD because of its necessity in supporting progress in the previous three pillars and in SD generally (United Nations et al., 2003). All these aspects are considered in Drastichova and Filzmoser (2019) (see more also in Drastichova (2018a) or Suchacek et al. (2018) in relation to spatial dimension of SD). The concept of SD can then be interpreted as a balance between its pillars, i.e. the economic, social and environmental pillar. In this paper, the focus is on the issues of health and wellbeing, because health can be understood as a crucial aspect of people's wellbeing. These aspects of health and wellbeing reflect Sustainable Development Goal 3 (SDG 3) in the EU SDG indicator set. The SDGs are a central part of the United Nation's 2030 Agenda, which was adopted by the United Nations (UN) in September 2015. SDG 3 aims to ensure health and wellbeing for all. These issues will be analysed in this context and they encompass the different dimensions (economic, social, environmental, as well as institutional). Not only must social aspects be considered (although they are the most significant for this issue), but also economic, environmental and institutional aspects.

The 2030 Agenda for SD and its 17 SDGs, which represent a recent policy framework worldwide, have provided an impetus to global efforts for pursuing SD. The EU, in coordination with its Member States, is committed to supporting the implementation of the 2030 Agenda. This agenda, its SDGs and their importance are described in more detail in (Bergman et al., 2018). The EU's response to this Agenda is included in the 2016 European Commission's Communication (European Commission, 2016). Since the EU adopted the topics of SDGs, replacing its SD strategy with them, the indicators included in the EU SDG indicator set represent the basis for the measurement of various aspects of SD. Two which are included in the topic of good health and wellbeing (SDG 3) were chosen for analysis in this paper. Health represents the basic constituent of wellbeing, while continuous increases in wellbeing should be the main aim of SD policies (see more in Drastichová (2018a), subsection 2.2.4, where the aspects related to the human development approach in term of SD are explained in detail).

Both the type of health system and the resources devoted to it affect the health of the population. The performance of the health system of different countries can be evaluated according to the relationship between resources and outcomes. ${ }^{1}$ A higher performance of a health system means that a country generates better health outcomes for the same level of resources or the same outcomes but with a lower level of resources. Health systems are financed either through taxes, in the case of healthcare services owned by the state, i.e. national health services, or through income-related social contributions, i.e. social security systems (Elola et al., 1995). In reality, different combinations exist, and other sources are used as well. A measurement of performance requires an explicit framework defining the goals of a health system against which outcomes can be judged and performance quantified (Smith, 1990). Healthcare evaluation can be understood as a critical assessment, through rigorous processes, of an aspect of healthcare to assess whether it meets its objectives. Several aspects of healthcare can be assessed, including effectiveness (the benefits of healthcare measured by improvements in health), efficiency (compares the cost of healthcare with the outputs or benefits obtained), acceptability (the social, psychological and ethical acceptability regarding the way people are treated in relation to healthcare) or equity (the fair distribution of healthcare amongst individuals/groups) (Blackwood, 2009). Efficiency metrics are of great importance for governing, managing and reforming any health system, and improving the management of its institutions (Cylus et al., 2016).

It is important to note that economists refer to two concepts of efficiency, which are allocative efficiency (AE) and technical efficiency (TE). AE can be focused on the choice of outputs or the choice of inputs. On the output side, it examines whether limited resources are used to produce the correct mix of healthcare outputs, given the preferences of funders, acting on behalf of society in general. With regard to input, AE examines whether an optimal mix of inputs is used to produce the chosen outputs, given the prices of those inputs. TE indicates the extent to which the system minimizes the use of inputs in producing its chosen outputs, regardless of the value placed on those outputs. It can be also said that it is maximizing its outputs given its chosen level of inputs. In either case, any variation in performance from the greatest feasible level of production indicates technical inefficiency, or waste (Cylus et al.,

\footnotetext{
${ }^{1}$ Many methods for the evaluation exist which are beyond the scope of this article.
} 
2016). Although different aspects are analysed in this paper, the above-mentioned concepts are considered in the analysis carried out in this paper. An even more important aspect than efficiency covered in this paper is the sustainability of health care systems. The main philosophy of sustainable development (SD) in compliance with its most quoted definition is considered.

The aim of the paper is to discover in the sample of 30 countries the effects of the components of healthcare expenditure by the provider on the indicators representing the effects of healthcare at the macroeconomic level. Regarding statistical methods, compositional data analysis and regression analysis are applied. We posed two main research hypotheses. Firstly, not only the overall amount of resources but also their composition can play a role in achieving desired health outcomes. Secondly, the structure of the expenditure patterns in the analysis can be similar in a particular group of countries within the overall sample investigated.

\section{Materials and Methods}

This section describes the scientific works which formed the basis for this paper, the methodology and the data used.

\subsection{Literature Review}

A number of works include health outcome indicators (or other indicators reflecting aspects of health) as part of the analysis of SD as a whole, health being an important constituent of wellbeing and SD. Others focus on effectiveness, efficiency, or sustainability of healthcare, or analyse specific aspects related to healthcare and the relationships between variables (including both macro- and micro-level analysis). The studies of Megyesiova and Lieskovska (2019) and Drastichova and Filzmoser (2019) need to be mentioned as the representatives of the first group. Both analysed SD indicators and applied the methods of cluster analysis and principal component analysis (PCA). The first study (among others) analysed relationships between healthcare expenditure and health outcomes (life expectancy (at birth and at the age 65), standardized death rates of noncommunicable diseases) in the OECD countries. They emphasised the importance of the analysis of indicators included in the SDG set in order to achieve SD. Drastichova and Filzmoser (2019) applied hierarchical cluster analysis (HCA) and PCA to the data of 12 indicators included in the EU SDG set in the $28 \mathrm{EU}$ countries and Norway in the period 2012-2016. The

\footnotetext{
${ }^{2}$ Different units can be used, such as total expenditure per capita, as \% of GDP, or as \% of public expenditure in total health expenditure.

${ }^{3}$ In terms of dependent variables, the vast majority of studies utilise mortality rates (age-specific or infant mortality in particular) and/or life expectancy (mainly at birth, but
}

indicators were selected to represent all the dimensions and crucial aspects of SD, while life expectancy at birth was chosen to represent SDG 3. This topic was taken as crucial for SD.

In the second group of works, the resources of health systems can be measured by several indicators such as healthcare expenditure ${ }^{2}$, number of physicians, number of hospital beds, etc. (Or, 2000; Ramesh and Mirmirani, 2007, Baltagi and Moscone, 2010; Jaba et al. (2014). Nixon and Ulmann (2006) reviewed key studies which consider the relationship between health expenditure, among other explanatory variables, and health outcomes, using macro-level data. This work reviewed key findings and methodological approaches in this field ${ }^{3}$. The authors also analysed the relationship between total healthcare expenditure and health outcomes in the former $15 \mathrm{EU}$ countries over the period 1980-1995, by means of a fixed-effects model conducted on panel data, using life expectancy (females and males) and infant mortality as the dependent variables. These two dependent variables were examined as the output of the healthcare system, and various life-style, environmental and occupational factors as inputs. Increases in healthcare expenditure over the period under analysis were significantly associated with major improvements in infant mortality, but made only a marginal contribution to the improvements in life expectancy in the EU countries. Infant mortality has been more than halved by the significant contribution of health expenditure and medical care (number of physicians), the predominant determinants of both male and female life expectancy are those contained in the constant term, namely the unaccountable salient variables and country-specific characteristics. According to these authors, relatively few studies have managed to find a link between healthcare expenditure and health outcomes, because there can be other principal factors affecting health outcomes, and particularly life expectancy (such as diet, life-style or environment).

A number of studies have assessed the impact of healthcare spending on health outcomes, usually reporting multiple estimates of the elasticity of health outcomes, most often measured by a mortality rate or life expectancy, with respect to healthcare spending. However, the extent to which study attributes influenced these elasticity estimates is not clear (Gallet et al., 2017). Gallet et al. (2017) utilized a meta-data set, consisting of 65 studies completed over the period 1969-2014, to examine the elasticity estimates using meta-regression analysis (MRA). The result is that healthcare spending has the greatest impact on the mortality rate, greater than on life expectancy.

also at specific ages). Ten of the 15 studies use income as an explanatory variable in addition to health expenditure, but there is a need to acknowledge, as several studies do, that the correlation between these two variables is high. These are also important findings for the analysis carried out in this work. 
MRA results showed that the spending elasticity for the mortality rate was particularly sensitive to data aggregation, the specification of the health production function, and the nature of healthcare spending. The spending elasticity for life expectancy was particularly sensitive to the age at which it was measured, and the decision to control for the endogeneity of spending in the health production function.

Jaba et al. (2014) analyzed the relationship between the dynamics of the inputs (healthcare expenditures per capita (current US\$)) and the outputs of healthcare systems (life expectancy at birth (years)). They applied a panel data analysis to data of 175 world countries, grouped according to the geographic position and income level in the period 1995-2010. They estimated life expectancy by a function of health expenditures. A significant relationship between health expenditures and life expectancy was identified. Country effects were significant and important differences between the countries exist.

Linden et al. (2017) analysed relationships between life expectancy at birth, public and private health expenditure with econometric panel time series methods for 34 OECD countries in the period 1970-2012. The countries were grouped in three clusters depending on size of public health expenditure as a share of GDP. The relationships between life expectancy and health expenditures were not uniform between the three groups of countries with different levels of public health expenditure as a share of GDP. When the share of public expenditure on health in GDP in a country is large, positive correlation between life expectancy and health expenditure was discovered. On the contrary, when this share is low, life expectancy and private health expenditure do not always support each other, but a significant positive link between public expenditure and life expectancy was still identified. Private and public health expenditure had similar positive effects on life expectancy in the cluster with the highest public share. These effects disappeared in clusters with a lower share and private effects turned negative in the cluster with the lowest share. The exogeneity of expenditure was ruled out as life expectancy has significant effects on both health expenditure in clusters with high and low shares. However, only in countries with high public shares do increases in life expectancy drive both public and private health expenditure upward. The authors also showed that larger public health expenditure led to higher private health expenditures, except in the USA.

$\mathrm{Lv}$ and $\mathrm{Xu}$ (2016) summarized the works which indicate a strong and positive relationship between national income and healthcare expenditure. As income is one of the main determinants of healthcare expenditure, the question arises of what the optimal amount of health spending for a society is. Recog- nizing this relationship should help policymakers to make judgments, plan health reforms, or achieve efficient allocation of resources. Accordingly, economic theory should determine what the optimal percentage share of GDP should be. The authors also pointed out that most of the literature on the determinants of health expenditure deals with the relationship between healthcare expenditure and income. An HCA for the evaluation of selected indicators representing healthcare inputs (current health care expenditure (percentage of GDP) and outcomes (life expectancy at birth and death rate due to chronic diseases) was applied in Drastichová (2018b).

Nixon and Ulmann (2006) confirmed that establishing causal relationships between health expenditure and health outcomes is complex and difficult because healthcare expenditure is only one of many quantitative and qualitative factors that contribute to health outcomes, and measurement of health status is an imperfect process. The innovation of our study lies in the application of an approach based on a regression analysis and compositional data analysis to the data on healthcare inputs and outcomes, while the data on inputs are classified according to their percentage shares in the whole (see the beginning of this subsection). The results of the previous studies concerning the relationships between healthcare inputs and health outcomes are considered, while this work concerns the relationships between the components of healthcare expenditure (their proportion or percentage) and health outcomes.

\subsection{Data and Methodology}

\subsubsection{Data}

All data for the indicators used are available on Eurostat (2019a). The indicator at the macroeconomic level applied in this paper for measuring healthcare inputs (resources) is the current health expenditure (CHE) (percentage of GDP). Healthcare expenditure is recorded in relation to the international classification for health accounts (ICHA), defining: healthcare expenditure by financing schemes (ICHA-HF), healthcare expenditure by function (ICHA-HC) and healthcare expenditure by provider (ICHA-HP). The last classification is applied in the analysis of this paper as an explanatory composition. It classifies units contributing to the provision of healthcare goods and services - such as hospitals, residential facilities, ambulatory health care services, ancillary services or retailers of medical goods. Healthcare providers are the organizations and actors that deliver healthcare goods and services as their primary activity, as well as those for which healthcare provision is only one among a number of activities (Eurostat, 2019b). The main items are defined in Table 1 . The first seven categories of expenditure (percentage of GDP) are used in the analysis (the remaining two are minor, and data for them are often unavailable). 
Table 1. Categories of current healthcare expenditure by provider (ICHA-HP), source: Eurostat (2019b)

Hospitals: the licensed establishments that are primarily engaged in providing medical, diagnostic and treatment services that include physician, nursing and other health services to inpatients and the specialised accommodation services required by inpatients and which may also provide day care, outpatient and home healthcare services (HOS);

Residential long-term care facilities: establishments that are primarily engaged in providing residential long-term care that combines nursing, supervisory or other types of care as required by the residents, where a significant part of the production process and the care provided is a mix of health and social services with the health services being largely at the level of nursing care in combination with personal care services (RES);

Providers of ambulatory healthcare: establishments that are primarily engaged in providing healthcare services directly to outpatients who do not require inpatient services, including both offices of general medical practitioners and medical specialists and establishments specialising in the treatment of day-cases and in the delivery of home care services (AMB);

Providers of ancillary services: establishments that provide specific ancillary type of services directly to outpatients under the supervision of health professionals and not covered within the episode of treatment by hospitals, nursing care facilities, ambulatory care providers or other providers (ANC);

Retailers and other providers of medical goods: establishments whose primary activity is the retail sale of medical goods to the general public for individual or household consumption or utilisation, including fitting and repair done in combination with sale (RET);

Providers of preventive care: organisations that primarily provide collective preventive programmes and campaigns/public health programmes for specific groups of individuals or the population-at-large, such as health promotion and protection agencies or public health institutes as well as specialised establishments providing primary preventive care as their principal activity (PRE);

Providers of healthcare system administration and financing: establishments that are primarily engaged in the regulation of the activities of agencies that provide healthcare and in the overall administration of the healthcare sector, including the administration of health financing (HSAF);

Rest of the economy; Rest of the world providers

As response variables, three indicators are used to reflect health outcomes at the macroeconomic level. The first indicator, healthy life years in absolute value at birth (HLY), is separately applied for men and women. Then, overall four indicators are used in the analysis. The indicator of HLY measures the number of remaining years that a person of specific age is expected to live without any severe or moderate health problems. The second one, life expectancy at birth (LE), is defined as the mean number of years that a new-born child can expect to live if subjected throughout his life to the current mortality conditions. It is one of the most frequently used health status indicators. The last one, death rate due to chronic diseases (DR), measures the standardised death rate of chronic diseases. The data are presented as standardised death rates, meaning they are adjusted to a standard age distribution in order to measure death rates independently of different age structures of populations. The LE and DR indicators are included in the SDG 3 topic of the EU SDG indicator set. While LE and DR indicators clearly refer to quantitative aspects of life, HLY also indicates qualitative aspects. LE is not able to show whether extra years of life gained through increased longevity are spent in good or bad health. Therefore, indicators of health expectancies, such as healthy life years have been developed. HLY focuses on the quality of life spent in a healthy state, rather than the quantity of life, as measured by LE (Eurostat, 2019a). It was considered desirable to include both types of indicators in the analysis. HLY was included in order to more clearly reflect the aspects in SDG 3. Data for all indicators are used for the 30 countries (the sample), and Switzerland, which was intended to be included in the analysis, but data for several expenditure components were missing.

The standard of living, measured by GDP per capita (in current prices, purchasing power standard (PPS) per capita, at market prices) (further only GDP per capita in PPS) is the last variable used in the analysis. Data from 2015 were used for the analysis, and data from 2016 were used, in addition, for calculation of the correlation coefficients.

\subsubsection{Methodology}

Regression analysis is the main methodology applied in this paper. Its goal is to explain the response variable $\mathrm{Y}$ using known explanatory variables $\mathrm{x}_{1}, \ldots, \mathrm{x}_{\mathrm{D}}$. A linear regression model can be written in terms of a conditional expected value as

$E(Y \mid x)=\beta_{0}+\beta_{1} x_{1}+\cdots+\beta_{D} x_{D}$,

with unknown parameters $\beta_{0}, \ldots, \beta_{\mathrm{D}}$ to be estimated, e.g. using the standard least squares (LS) method. However, this approach is fully reasonable when both the response $\mathrm{Y}$ and the covariates $\mathrm{x}=\left(\mathrm{x}_{1}, \ldots\right.$, $\mathrm{x}_{\mathrm{D}}$ )' carry absolute information (represented often by variables corresponding to physical units). However, the explanatory variables can describe relative contributions of the components on the whole. In such a case, the sum of the variables (parts) is not important and the only relevant information is contained in the ratios between these parts. Often, such data, named compositional data or compositions (Aitchison, 1986) are represented in proportions or percentages and are characterized by a constant sum constraint ( 1 or 100, respectively) (Hron et al., 2012). Accordingly, compositional data analysis, which involves the analysis of compositional data (i.e. data that measure parts of a whole, such as percentages, pro- 
portions), is applied in this paper. Compositional explanatory variables should not be directly used in a linear regression model because any inference statistic can become misleading. While various approaches for this problem were proposed, here an approach based on isometric logratio (ilr) coordinates is used. This means that the composition is expressed in the usual Euclidean geometry using orthonormal coordinates. For $D$ compositional parts, $D-1$ coordinates need to be constructed. For reasons of interpretability, so-called pivot coordinates are used, being defined as

$z_{i}=\sqrt{\frac{D-i}{D-i+1}} \ln \frac{x_{i}}{\sqrt{D-i} \sqrt{\prod_{j=i+1}^{D} x_{j}}}, i=1, \ldots, D-1$,

(Fiserova and Hron, 2011). The first coordinate $\mathrm{z}_{1}$ covers all relative information about part $\mathrm{x}_{1}$, and $\mathrm{x}_{1}$ does not appear in any of the other coordinates. Therefore, $\mathrm{Z}_{\mathrm{l}}$ can be interpreted in terms of $\mathrm{x}_{1}$, which will be important here for the statistical inference in regression analysis. For this purpose, the idea is to construct pivot coordinates for each single explanatory variable, estimate the regression parameters and derive the statistical inference, and then report just the coefficient and the inference information of the first pivot coordinate. This creates an inference table with the information of all first coordinates of the respective pivot coordinate systems. The corresponding regression coefficient refers to a logratio of the respective part on an average behaviour of the remaining parts in the composition. Consequently, the interpretation can be done in an analogous way as it is done in standard regression. If the coefficient is positive, this variable is dominant in the composition within the model, while if it is negative, the opposite is true (Hron et al., 2012).

This procedure is implemented in the function $1 \mathrm{mCo}-$ DaX (Classical and robust regression of non-compositional (real) response on compositional predictors) of the R package robCompositions (Hron et al., 2012). It must be noted that the classical leastsquares regression is very sensitive to data outliers, and therefore robust regression is used. Most importantly, also the inference statistic is robust. Function $\operatorname{lmCoDaX}$ by default takes robust regression (Maronna, Martin and Yohai, 2006). Note that the multiple R-square is the same for every pivot coordinate system (Hron et al., 2012). For further details we refer to Filzmoser et al. (2018).

\section{Results}

Section 3.1 presents the results of the regression analysis and the compositional data analysis and section 3.2 contains a detailed analysis of the results and discussion.

\subsection{Relationships between healthcare expenditure and healtcare outcomes}

Table 2 shows the results of four regression analyses. In each of them the same composition of CHE (per- centage of GDP) classified by provider is used along with a different response variable. From the seven component variables, representing expenditure ratios on particular healthcare providers, overall, only five were statistically significant. Depending on the response variable, one, two or three components of expenditure were statistically significant.

Table 3 displays R-squared and p-values for each of the four models. All models are statistically significant and the highest value of adjusted R-squared is achieved for the response variable LE. It is clear that other factors affect the health outcome indicators as well. The standard of living, measured by GDP per capita in PPS was included in all models as a noncompositional explanatory variable but it was proved as statistically insignificant in each model. Therefore, only the model containing compositional data was used.

Three response variables are applied in the model, while the first of them, HLY, is separately used for men (HLYm) and women (HLYf). As regards HLYf, the statistically significant variables in the structure of expenditure are those on residential long-term care facilities (RES), where the dominance of the variable was confirmed and on the providers of ambulatory healthcare (AMB), where the opposite is true. So, when in the composition of expenditure, the variable RES as a ratio to GDP is increasing and thus getting more dominant in the composition, it is connected with higher values of HLYf. When the variable AMB is decreasing and thus getting less dominant in the composition, it leads to higher levels of HLYf in the sample. For HLYm, the same applies to the expenditure on residential longterm care facilities (RES), but another statistically significant variable is that representing expenditure on providers of healthcare system administration and financing (HSAF). However, this variable is not dominant. Accordingly, when the variable RES as a ratio to GDP is getting more dominant in the composition, it is connected with higher values of HLYm in the sample. When HSAF is decreasing relative to an average of the remaining parts in the composition, it leads to higher values of HLYm in the examined sample. For the LE indicator, three components of expenditure are statistically significant. Those on providers of ancillary services (ANC) and on retailers and other providers of medical goods (RET) are not dominant. The dominance of expenditure on providers of healthcare system administration and financing (HSAF) was confirmed. So, for this response variable, its higher value is connected with more dominance of the last kind of expenditure.

Lower levels of previous two kinds of expenditure are connected with higher LE values. For the DR indicator, only the expenditure on retailers and other providers of medical goods (RET) is statistically significant and the dominance of this variable is confirmed. So, the more dominant (in the composition) this expenditure gets, the higher the values for this response $(\mathrm{DR})$ is. 
Table 2. Results of regression analysis for four different response variables, source: author's calculations

\begin{tabular}{|c|c|c|c|c|c|c|c|c|c|}
\hline HLYm & Estimate & Std. Er. & $\mathbf{t}$ val. & $\operatorname{Pr}(>|\mathbf{t}|)$ & HLYf & Estimate & Std. Er. & $\mathbf{t}$ val. & $\operatorname{Pr}(>|\mathbf{t}|)$ \\
\hline Int. & 70.3809 & 9.1896 & 7.659 & $<0.0005^{* * *}$ & Int. & 59.937 & 11.145 & 5.378 & $<0.0005^{* * *}$ \\
\hline HOS & -10.2768 & 6.4772 & -1.587 & 0.1283 & HOS & 10.309 & 8.749 & 1.178 & 0.2507 \\
\hline RES & 3.0962 & 1.2898 & 2.400 & $0.0262^{*}$ & RES & 3.590 & 1.730 & 2.074 & $0.0494 *$ \\
\hline AMB & 6.0906 & 4.2586 & 1.430 & 0.1681 & AMB & -16.933 & 6.359 & -2.663 & $0.0139 *$ \\
\hline ANC & 2.7124 & 2.2610 & 1.200 & 0.2443 & ANC & -2.021 & 1.825 & -1.107 & 0.2796 \\
\hline RET & 2.1759 & 3.198 & 0.680 & 0.5041 & RET & 5.051 & 4.803 & 1.052 & 0.3039 \\
\hline PRE & 0.8626 & 1.1453 & 0.753 & 0.4601 & PRE & 1.943 & 1.845 & 1.053 & 0.3033 \\
\hline HSAF & -4.6611 & 1.7509 & -2.662 & $0.0150^{*}$ & HSAF & -1.939 & 2.675 & -0.725 & 0.4760 \\
\hline LE & Estimate & Std. Er. & $\mathbf{t}$ val. & $\mathbf{P r}(>|\mathbf{t}|)$ & DR & Estimate & Std. Er. & $\mathbf{t}$ val. & Pr$(>|\mathbf{t}|)$ \\
\hline Int. & 81.39357 & 3.18593 & 25.548 & $<0.0005^{* * *}$ & Int. & 176.258 & 52.825 & 3.337 & $0.00275^{* *}$ \\
\hline HOS & 3.17027 & 2.49787 & 1.269 & 0.21970 & HOS & -60.087 & 41.805 & -1.437 & 0.16354 \\
\hline RES & -0.09279 & 0.53332 & -0.174 & 0.86371 & RES & -4.576 & 8.244 & -0.555 & 0.58398 \\
\hline AMB & -1.78646 & 1.83250 & -0.975 & 0.34187 & AMB & -14.991 & 26.423 & -0.567 & 0.57596 \\
\hline ANC & -1.18831 & 0.55724 & -2.132 & $0.04623^{*}$ & ANC & 5.139 & 8.744 & 0.588 & 0.56217 \\
\hline RET & -3.84207 & 1.37628 & -2.792 & $0.01163 *$ & RET & 87.587 & 20.782 & 4.214 & $<0.0005^{* * *}$ \\
\hline PRE & -0.15604 & 0.62471 & -0.250 & 0.80544 & PRE & 2.547 & 8.818 & 0.289 & 0.77522 \\
\hline HSAF & 3.89540 & 1.30347 & 2.988 & $0.00755^{* *}$ & HSAF & -5.484 & 12.604 & -0.435 & 0.66735 \\
\hline
\end{tabular}

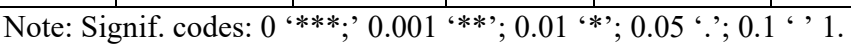

Table 3. Other features of the models for four (different) response variables, source: author's calculations

\begin{tabular}{|c|c|c|c|c|c|c|c|}
\hline HLYm & $\begin{array}{c}\text { Multiple } \\
\mathbf{R}^{\mathbf{2}}\end{array}$ & $\begin{array}{c}\text { Adjusted } \\
\mathbf{R}^{\mathbf{2}}\end{array}$ & $\mathbf{p}$-value & HLYf & $\begin{array}{c}\text { Multiple } \\
\mathbf{R}^{\mathbf{2}}\end{array}$ & $\begin{array}{c}\text { Adjusted } \\
\mathbf{R}^{\mathbf{2}}\end{array}$ & $\mathbf{p}$-value \\
\hline & 0.506 & 0.357 & 0.01742 & & 0.4603 & 0.319 & 0.01789 \\
\hline LE & $\begin{array}{c}\text { Multiple } \\
\mathbf{R}^{\mathbf{2}}\end{array}$ & $\begin{array}{c}\text { Adjusted } \\
\mathbf{R}^{\mathbf{2}}\end{array}$ & $\mathbf{p}$-value & DR & $\begin{array}{c}\text { Multiple } \\
\mathbf{R}^{\mathbf{2}}\end{array}$ & $\begin{array}{c}\text { Adjusted } \\
\mathbf{R}^{\mathbf{2}}\end{array}$ & $\mathbf{p}$-value \\
\hline & 0.7592 & 0.683 & $<0.0005$ & & 0.6584 & 0.573 & $<0.0005$ \\
\hline
\end{tabular}

Note: $\mathrm{R}^{2}-\mathrm{R}$-squared.

Although the positive relationship between the healthcare expenditure and health outcomes was confirmed by a number of authors, there is no unambiguous result which kind of expenditure should have a dominant share in GDP when different health outcomes are applied. For both HLY indicators, it seems to be desirable to increase the ratio of expenditure on residential long-term care facilities in the composition. Nevertheless, the lower ratio of expenditure on ambulatory healthcare in the case of HLYf and on providers of healthcare system administration and financing in the case of HLYm are connected with their higher levels. The last-mentioned expenditure as a component in the structure of expenditure is also associated with higher LE values, which is in conflict with negative effects on HLYm in the structure. However, for both response variables, this occurs by simultaneous changes of ratios of other statistically significant expenditure. Moreover, for both LE and DR, an unfavorable relationship between the variable and the ratio of expenditure on retailers and other providers of medical goods is confirmed. This makes sense between LE and DR negative correlation exists. Accordingly, the effect of this kind of expenditure seems to be less ambiguous and more straightforward, as it is related to both the length of life and death rates. However, no relationship was found between its ratio and indicators reflecting quality of life (HLY).
Although in absolute values each component of expenditure is crucial for increasing health outcomes, it is confirmed that in relative values the results can be quite different. Moreover, countries face different conditions and challenges and generally, many other factors can affect relationships between healthcare inputs and outcomes.

In Figure 1, which reflects the predictions of the four models (described in Table 1 and 2), some outliers are visible. The concrete values of variables are analyzed in subsection 3.2 in more detail. The Netherlands is a significant outlier for both HLY indicators (see Figure 1 (a), (b)). It showed poor results in both HLY indicators although the performance in other two response variable is relatively good. Similarly, Luxemburg (an outlier for DR - Figure 1 (d)) showed one of the best results for LE and DR and the performance in both HLY indicators is lower. It showed the third lowest CHE ratio in the sample, while the Netherlands had the fifth highest (when also Switzerland is included). Denmark and Finland are outliers, in particular for both HLY indicators, and, in the case of Denmark, also for the LE indicator (Figure 1 (a), (b), (c)). Although these countries showed high CHE ratios, the performance in HLY indicators and that of Denmark also in other two response variables are lower (see subsection 3.2.). Moreover, Denmark showed the highest ratio of expenditure on hospitals in the sample (see Table 4 in 

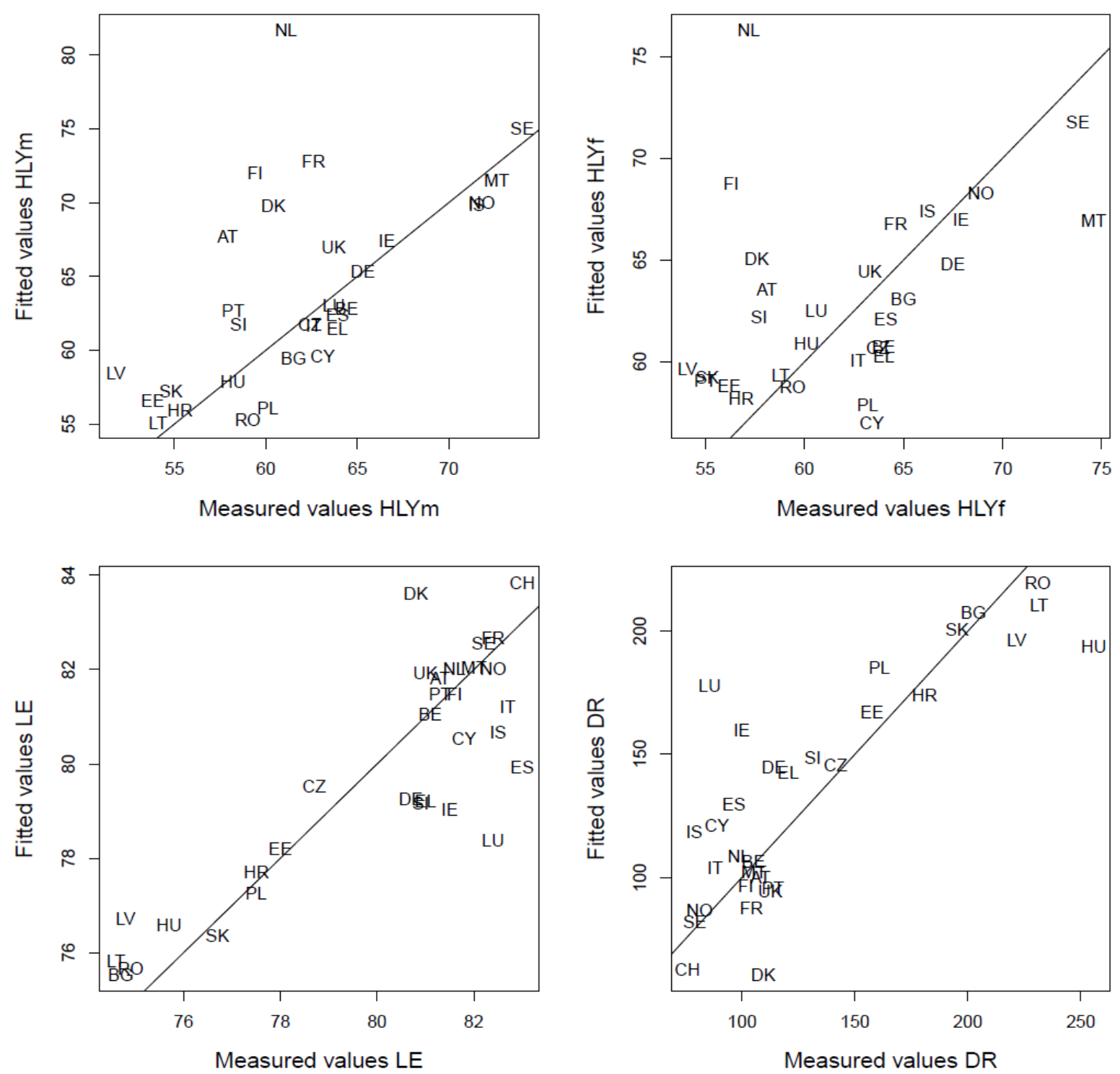

Figure 1. Measured values and fitted values: (a) HLYm; (b) HLYf; (c) LE; (d) DR, source: author's calculations

subsection 3.2), which is similar to other countries with the highest ratios of overall CHE. These are France, Sweden, Switzerland and Norway, which often showed the high performance in the response variables.

\subsection{Detailed analysis of results and discussion}

As regards the relationships between the indicators applied, the negative correlation between the LE and DR indicator is obvious (the correlation is below 0.96 in both 2015 and 2016). There is a clear positive correlation between two HLY indicators $(0.904$ and 0.898 in 2015 and 2016 respectively). However, a higher positive correlation can only be found between LE and HLYm (0.674 and 0.626 in 2015 and 2016 respectively). It was low between LE and HLYf (0.415 and 0.358 in 2015 and 2016 respectively). For both years the correlation between the overall CHE and GDP per capita in PPS this coeffi- cient was very low and positive (0.321 and 0.297 in 2015 and 2016 respectively). Medium value is achieved when Luxembourg is left out of the analysis ( $r=0.666$ in 2015). This country represents an outlier because it showed the highest GDP per capita and the third lowest ratio of overall CHE. Moreover, GDP per capita and the overall CHE ratio showed a medium level of correlation with the DR and LE indicators (the coefficients were around 0.6 for both DR and LE in absolute values in both 2015 and 2016, while there is a negative correlation between GDP per capita/CHE ratio and DR and a positive correlation between GDP per capita/CHE ratio and LE). Between GDP per capita/CHE ratio and HLY indicators the coefficient was very low (and positive). Accordingly, GDP per capita was insignificant when used as a non-compositional explanatory variable in the regression analyses presented in Table 1 . Figure 2 displays overall expenditure ratios for 2015 and 


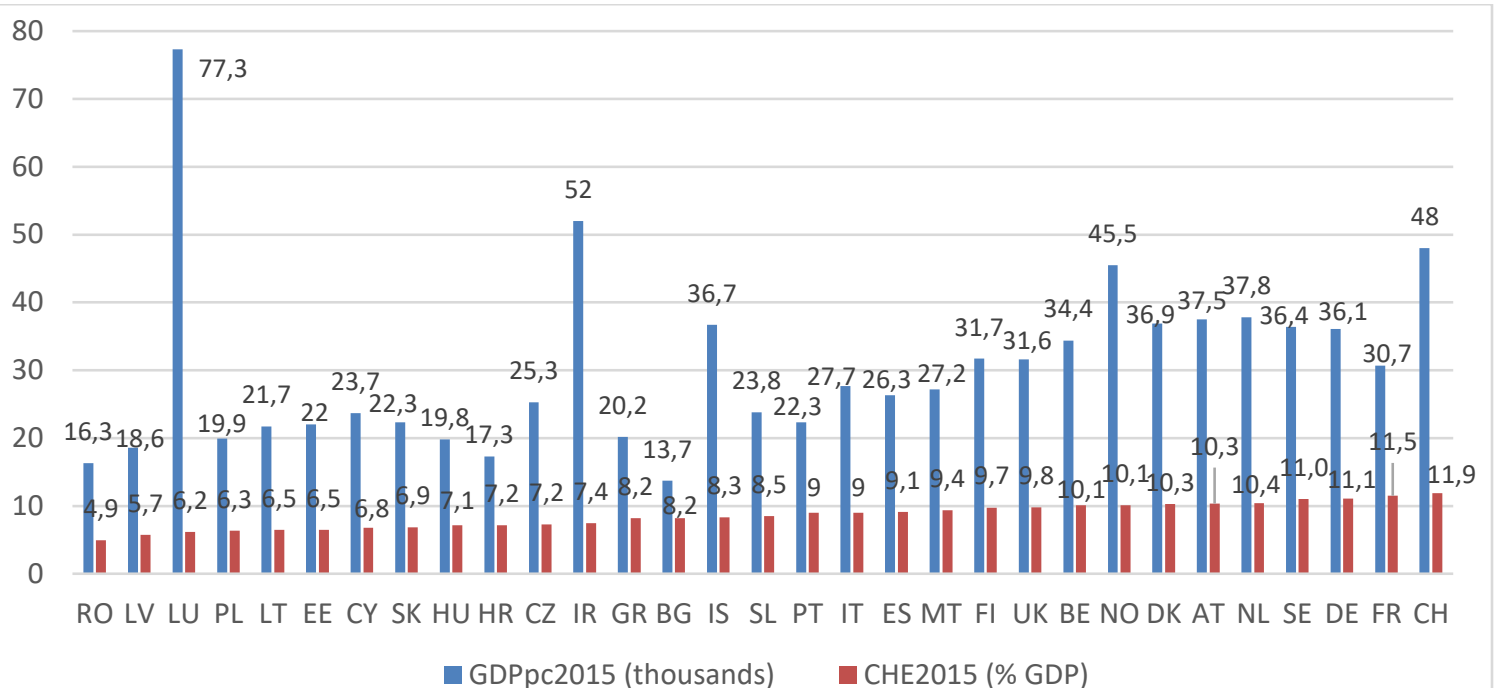

Figure 2. CHE (percentage of GDP) and GDP per capita in PPS in the EU countries, Iceland, Norway and Switzerland, source: Eurostat (2019a)

Table 4. Countries with the five highest and five lowest values for the indicators, 2015, source: author's calculations

\begin{tabular}{|c|c|c|c|c|c|}
\hline V & H & L & V & H & L \\
\hline HOS & $\begin{array}{c}\text { DK, FR, SE, CH, NO, } \\
\text { UK }\end{array}$ & LV, RO, LU, LT, PL & HSAF & FR, DE, CH, NL, BE & NO, FI, IC, BG, CY \\
\hline RES & $\begin{array}{c}\text { NL, SE, CH, NO, FI, } \\
\text { IE }\end{array}$ & SK, BG, HR, RO, GR & HLYf & MT, SE, NO, IR, DE & LV, PT, SK, EE, FI \\
\hline AMB & $\begin{array}{c}\text { BE, CH, DE, FI, DK, } \\
\text { NO }\end{array}$ & RO, SK, BG, LV, LT & HLYm & SE, MT, NO, IC, IR & LV, EE, LT, SK, HR \\
\hline ANC & SK, CY, PT, LV, GR & SE, SL, NO, IR, EE & LE & $\begin{array}{r}\text { CH, ES, IT, IS, NO, } \\
\text { LU }\end{array}$ & LT, BG, LV, RO, HU \\
\hline RET & BG, GR, SK, HU, DE & LU, IR, DK, NO, CH & DR & HU, LT, RO, LV, BG & CH, IC, SE, NO, LU \\
\hline PRE & NO, IT, NL, UK, SE & PL, PT, FI, LV, RO & GDP & $\begin{array}{r}\text { LU, IR, CH, NO, NL, } \\
\text { AT }\end{array}$ & BG, RO, HR, LV, HU \\
\hline
\end{tabular}

Note 1: $\mathrm{H}$ - highest; $\mathrm{L}$ - lowest; $\mathrm{V}$ - variable; GDP - GDP per capita.

Note 2: The highest values are ordered from the highest and the lowest values from the lowest. When Switzerland shows the indicated value, six countries are displayed.

GDP per capita for the countries in the sample and Switzerland. This Figure shows that the relationship between the displayed variables is not clear but it would be stronger after omitting some outliers. Apart from Malta, Slovenia and Bulgaria, the new member countries had relatively low CHE ratios, the Southern countries showed medium values and the more developed countries predominantly showed relatively high values (except for Ireland and Iceland). Table 4 displays countries with the highest and lowest values of all indicators used in the analysis, including GDP - per capita. Switzerland is included as well (if its value is displayed, then six values are shown). This can help manifest the relationships between the explanatory variables (seven types of healthcare expenditure) and the response variables. Table 4 shows that countries with the highest (or relatively high) $\mathrm{CHE}$ ratios (see Figure 2) also have the highest (or relatively high) ratios of expenditure on hospitals, residential long-term care facilities, providers of ambulatory healthcare, providers of preventive care and providers of healthcare system ad- ministration and financing. They often exhibited low values of expenditure ratios on providers of ancillary services and retailers and other providers of medical goods and a relatively high performance in the response variables. However, there are several exceptions. Ireland and Iceland had among the highest expenditure ratios on residential long-term care facilities, but the overall CHE is relatively low in Ireland and medium in Iceland. For providers of ambulatory healthcare, the expenditure ratio of the Netherlands is relatively low although its overall ratio is one of the highest and the same applies to Germany in the case of providers of preventive care. As regards providers of healthcare system administration and financing, the UK exhibited a ratio slightly lower than the average. However, Finland, whose expenditure ratio is also among the highest, exhibited the second lowest ratio for this component. Switzerland, which showed the highest CHE ratio, had medium values for providers of ancillary services and Belgium, Austria and France exhibited relatively high values. As regards retailers and other providers of medical goods, Germany along with France showed rela- 
tively high ratios and those of Austria were medium. All five Northern countries showed relatively low ratios for these two types of expenditure along with a high performance in the response variables (outcomes), except for Finland and more so Denmark, which showed poorer results.

Regarding HLY indicators, Ireland and Iceland showed one of the highest HLY indicators, Bulgaria showed a relatively high value of HLYf. The Netherlands and Austria exhibited relatively low values of HLYf. Austria also had a low HLY value, while those of the Netherlands and France were medium. Denmark and Germany exhibited only medium values of LE while those of Spain, Italy and Iceland are among the highest. This is also similar for DR where Cyprus had one of the lowest values and those of Denmark and Germany were higher.

Countries with lower overall expenditure ratios exhibited low expenditure ratios on hospitals and providers of ambulatory healthcare. They predominantly showed higher ratios on providers of ancillary services and retailers and other providers of medical goods and often lower ratios for the remaining categories. These countries often showed a relatively low performance in the response variables. However, there are exceptions again.

Notably, France had the highest CHE ratio in the EU, and had relatively high ratios in all other analyzed components; although its GDP per capita was only medium. It achieved very good results in the response variables, except for a slightly lower value of HLYm. Switzerland, having the lowest DR and the highest LE, along with the highest $\mathrm{CHE}$ ratio, showed typical features of the developed countries, i.e. low ratios for providers of ancillary services and retailers and other providers of medical goods, while the other ratios are among the highest in the sample. This is also a country with one of the highest standards of living in the sample. Norway and Sweden, exhibiting among the best results in all response variables and among the highest standards of living and overall CHE ratios, are in most aspects related to expenditure ratios similar to Switzerland. Expenditure ratios on hospitals, residential long-term care facilities, providers of ambulatory healthcare and providers of preventive care were similarly high, but on providers of healthcare system administration and financing they differed significantly. Norway had the lowest ratio in the sample, Sweden had a relatively low value as well, while that of Switzerland was one of the highest in the sample. Ratios for providers of ancillary services were among the lowest in Sweden and Norway, i.e. much lower than those in Switzerland.

Iceland, which showed very good results in all response variables and has one of the highest standards of living, differs slightly from the majority of the developed countries which performed well in the response variables. It had relatively low ratios of expenditure on providers of preventive care and pro- viders of healthcare system administration and financing. Another small country, Luxembourg, which exhibited among the best results in DR and LE indicators and had one of the highest standards of living, had lower ratios of expenditure on hospitals, providers of ambulatory healthcare and providers of preventive care. However, its relatively low expenditure ratio on providers of ancillary services and the lowest ratio on retailers and other providers of medical goods are in line with the majority of the developed countries. Smaller countries often face distinctive conditions, so these two countries can nevertheless be regarded as among the most developed countries, although their overall expenditure ratios are lower.

Lithuania, Bulgaria, Latvia, Romania and Hungary display the poorest performances in both DR and LE. As regards HLY indicators, there are also other countries with a poorer performance. In particular, Slovakia and Croatia performed among the worst, as well as having poor results in both LE and DR. Moreover, Bulgaria showed better results in HLY indicators, especially in HLYf. Common features of these seven countries are low ratios of expenditure on hospitals, long-term residential care facilities, providers of ambulatory healthcare, providers of preventive care and providers of healthcare system administration and financing. On the other hand, they exhibit high ratios for providers of ancillary services (except for Lithuania and Hungary) and retailers and other providers of medical goods. Only Slovakia and Croatia exhibited higher ratios for providers of preventive care and providers of healthcare system administration and financing. All of these countries also showed the lowest standards of living measured by GDP per capita (see Figure 2; only that of Slovakia is slightly higher).

Overall, it is obvious that the relationships between standards of living/expenditure ratios and their components and the response variables are not that straightforward, especially for the two qualitative variables. However, some patterns were detected.

\section{Discussion}

According to Cylus et al. (2016) AE can also be considered at a broad sectoral level to examine whether the correct mix of health services is funded, so that at a given aggregate level of expenditure, health outcomes are maximized, which means, for example, that an efficient allocative health system would allocate funds between sectors such as prevention, primary care, hospital care, and long-term care so as to deliver the maximum level of health-related outcomes in line with societal preferences. This was also investigated in the paper and it is desirable to deal with the composition of expenditure from different points of view (see subsection 2.2.1) in order to increase the efficiency of health systems. Thus, it is important not only to determine what the optimal 
percentage share of GDP for overall CHE should be, but also its allocation into particular components.

As Goldacre (1996) claims, the evidence for a causal link between health care expenditure and health outcomes remains elusive as problems emerge from the difficulty of isolating the contribution of the health service input as a determinant of health status output This frustrates attempts to measure the overall effectiveness and efficiency of healthcare. Moreover, it can be difficult to find a significant relationship between standards of living and CHE ratios (\% of GDP), and between standards of living and health outcomes measured by the four response variables used in the group of developed countries, which show no significant differences in values for these variables.

The composition of expenditure clearly revealed certain patterns dividing the countries into at least two groups. Accordingly, the analysis of the composition of expenditure can provide some guidance. From the practical point of view, it is required that policymakers set out clearly what they mean by efficiency and give local decision-makers the leadership capacity and autonomy necessary to pursue improved efficiency. They should also ensure that there are information systems which measure progress accurately and in a timely fashion. Based on this, efficiency metrics can play a more prominent role in policymaking and relevant decisions. Moreover, all these decisions should be incorporated into the framework of pursuing the path of SD, i.e. into strategies of SD.

\section{Conclusions}

The aim of the paper was to discover in the sample of 30 countries the effects of the components of healthcare expenditure by the provider on the indicators representing the effects of healthcare at the macroeconomic level. The indicators reflecting health outcomes were chosen carefully, taking into consideration the EU's priorities in SD and the indicators included in the EU SDG indicator set, and also taking into account that health is a crucial constituent of wellbeing and the main outcome of the strategies aimed at SD. The EU countries, and Norway and Iceland were investigated. Switzerland, for which data for both HLY indicators were missing, was included in comparisons of all other indicators. The data of Eurostat (2019) in 2015 were used. Compositional data analysis, regression analysis and cluster analysis were applied as the main methods. In the sample of countries, many similar features were discovered, although several outliers were also present.

The results in the sample indicate that the higher the ratio of expenditure on retailers and other providers of medical goods in relation to other types of expenditure in the composition, the higher the DR indicator and the lower the LE indicator. The ratio of expenditure on residential long-term care facilities in the composition seems to have had a positive effect on both HLY indicators. The effect of expenditure ratios on providers of healthcare system administration and financing is not straightforward. This ratio had an effect on the composition of two variables: a negative impact on HLYm was identified, and there was a positive impact on LE indicators. Another two components of expenditure had negative effects on the response variables in the composition, namely: expenditure ratios on providers of ambulatory healthcare in the case of HLYf, and on providers of ancillary services in the case of the LE indicator. Therefore, the first research hypothesis is confirmed. The standard of living, as measured by GDP per capita in PPS, did not significantly correlate with overall CHE ratios or the response variables. The relationships would be stronger if outliers were omitted. Since all countries in the sample were developed countries and the values of all variables exhibited no significant differences, the structures of expenditure analyzed in this paper had similar patterns, and two groups of countries were identified.

Countries with the highest (or relatively high) overall expenditure ratios also have the highest (or relatively high) ratios of expenditure on hospitals, residential long-term care facilities, providers of ambulatory healthcare, providers of preventive care and providers of healthcare system administration and financing. They often exhibited low values of expenditure ratios on providers of ancillary services and retailers and other providers of medical goods and a relatively high performance in the response variables. Overall, Norway, Sweden, Iceland and Switzerland (used only for comparisons) achieved the best results in outcomes along with highest values of GDP per capita and CHE ratios (both except for Iceland, which is a small country that could have extraordinary conditions).

Countries with lower values of overall expenditure ratios exhibited low expenditure ratios on hospitals and providers of ambulatory healthcare. They had predominantly higher ratios on providers of ancillary services and retailers and other providers of medical goods and often lower ratios for the remaining categories. Countries with the poorest results are Hungary, Lithuania, Romania, Latvia and Bulgaria. These are the countries with low standards of living, relatively low $\mathrm{CHE}$ ratios (except for Bulgaria), the lowest LE and highest DR values. Slovakia and Croatia, exhibiting slightly higher performance in DR and LE, can be added to this group, as they had very low HLY values as well, while those of Bulgaria are higher. Slovakia and Croatia differ from the other five countries (and general features of countries with poor results) in their higher ratios for providers of preventive care and providers of healthcare system administration and financing. Accordingly, the second hypothesis is confirmed. Since the aspects of the relationship between health and wellbeing are crucial for SD, these results should be considered in strategies for SD in the EU as a whole, in member 
states, and at lower levels. Furthermore, they should be incorporated into decisions taken regarding healthcare and other policies which affect wellbeing and overall SD. The countries which performed poorly should be inspired by the composition of the expenditure of those which performed better.

It is a comprehensive task to evaluate the relationships between the resources devoted to the health system and its outcomes, since healthcare expenditure is only one of many quantitative and qualitative factors that contribute to health outcomes. It is not only the overall amount of resources but also their composition that can play a role in achieving desired health outcomes. Several patterns were discovered in this analysis. In order to increase effectiveness, efficiency as well as sustainability of health systems it is necessary to investigate all relevant aspects at different levels and their interconnections. The methodology applied is a challenging task, as is the role of policymakers in improving efficiency based on the efficiency metrics applied. A focus on these aspects should be a crucial part of the measurement of sustainability and the path towards SD, while compositional data analysis could be a part of the appropriate methodology for this measurement.

\section{References}

1. AITCHISON J. 1986, The Statistical Analysis of Compositional Data, Chapman \& Hall, London.

2. BALTAGI B., MOSCONE F., 2010, Health Care Expenditure and Income in the OECD Reconsidered: Evidence from Panel Data, IZA Discussion Paper, paper \#4851.

3. BLACKWOOD R., CURRIE C., 2009, 2016, Study design for assessing effectiveness, efficiency and acceptability of services including measures of structure, process, service quality, and outcome of health care, https:// www.healthknow ledge.org.uk/public-health-textbook/research-methods/1c-health-care-evaluation-health-care-assessment/study-design-assessing-effectiveness (18.09.2019).

4. BERGMAN Z., BERGMAN M. M., FERNANDES K., GROSSRIEDER D., SCHNEIDER L., 2018, The Contribution of UNESCO Chairs toward Achie-ving the UN Sustainable Development Goals, in: Sustainability, 10(12), DOI:10.3390/su10124471.

5. CYLUS J. PAPANICOLAS I., SMITH P. C., 2016, Health system efficiency How to make measurement matter for policy and management, in: Health Policy Series, 46, 242 p.

6. DRASTICHOVA M., 2018a, The Theory and Measurement of Sustainable Development, 3rd ed.; SAEI, 52. VSBTU Ostrava: Ostrava, Czechia, $420 \mathrm{p}$.

7. DRASTICHOVA M., 2018b, Evaluation of Selected Indicators in the Social Dimension of Sustainable Development, in: Proceedings of the 12th International Scientific Conference INPROFORUM 2018 Innovations, Enterprises, Regions and Management, Jihočeská univerzita $\mathrm{v}$ Českých Budějovicích, České Budějovice, p. 182-190.

8. DRASTICHOVA M., FILZMOSER P., 2019, Assessment of Sustainable Development Using Cluster Analysis and Principal Component Analysis, in: Problemy Ekorozwoju/ Problems of Sustainable Development, 14(2), p. 724.

9. ELOLA J., DAPONTE A., NAVARRO V., 1995, Health Indicators and the Organization of Health Care Systems in
Western Europe, in: Am J Public Health, 85(10), p. 1397 1401.

10. European Commission, Next steps for a sustainable European future. European action for sustainability, Communication from the Commission to the European Parliament, the Council, the European Economic and Social Committee and the Committee of the Regions, $\operatorname{COM}(2016) 739$ final.

11. Eurostat, 2019a, Eurostat Database, https://ec.europa.eu/eurostat/data/database (10.09.2019).

12. Eurostat, 2019b, Health care expenditure (SHA 2011) (hlth_sha11) (2019b)., https://ec.europa.eu/ eurostat/ cache/metadata/en/hlth_sha11_esms.htm (18.09.2019).

13. FISEROVA E., HRON K., 2011, On interpretation of orthonormal coordinates for compositional data, in: Mathematical Geosciences 43(4), p. 455-468, DOI: 10.1007/s11004-011-9333-x.

14. FILZMOSER P., HRON K., TEMPL M., 2018, Applied Compositional Data Analysis. With Worked Examples, in: $R$. Springer Series in Statistics, Springer Nature Switzerland AG, Cham, $292 \mathrm{p}$.

15. GALLET C.A., DOUCOULIAGOS H., 2017, The impact of healthcare spending on health outcomes: A metaregression analysis, in: Social Science \& Medicine, 179, p. 9-17.

16. GOLDACRE M., 1996, Health outcomes from a medical perspective, in: Health Outcomes: Biological, Social, and Economic Perspectives, ed. Macbeth H.M., Oxford University Press, Oxford.

17. HRON K., FILZMOSER P., THOMPSON K., 2012, Linear regression with compositional explanatory variables, in: Journal of Applied Statistics, 39, p. 1115-1128.

18. JABA E., BALANA C.B, ROBUA I.-B., 2014, The relationship between life expectancy at birth and health expenditures estimated by a cross-country and time-series analysis, in: Procedia Economics and Finance, 15, p. 108114.

19. LINDEN M., RAY D., 2017, Life expectancy effects of public and private health expenditures in OECD countries 1970-2012: Panel time series approach, in: Economic Analysis and Policy, 56, p. 101-113.

20. LV Z., XU T., 2016, Does intelligence affect health care expenditure? Evidence from a cross-country analysis, in: Intelligence, 55 , p. 86-89.

21. MARONNA R.A., DOUGLAS R.D., YOHAI V.J., 2006, Robust Statistics: Theory and Methods, John Wiley \& Sons, Ltd., Chichester.

22. MEGYESIOVA S., LIESKOVSKA V., 2018, Analysis of the Sustainable Development Indicators in the OECD Countries, in: Sustainability, 10, DOI: $10.3390 / \mathrm{su} 10124554$.

23. NIXON J., ULMANN P., 2006, The relationship between health care expenditure and health outcomes, in: The European Journal of Health Economics, 7(1), p. 7-18.

24. OR Z., 2000, Determinants of health outcomes in industrialised countries: a pooled cross-country, time-series analysis, in: OECD Economic Studies, 30(1), p. 53-77.

25. RAMESH M., MIRMIRANI S., 2007, An Assessment of OECD Health Care System Using Panel Data Analysis, in: Southwest Business \& Economics Journal,16, p. 21-35.

26. SMITH P., 1990, The Use of Performance Indicators in the Public Sector, in: Journal of the Royal Statistical Society Series A, 153(1), p. 53-72, DOI: 10.2307/2983096.

27. SUCHACEK J., WALANCIK M., WRÓBLEWSKI L., URMINSKY J., DRASTICHOVA M., SOTKOVSKY I., 2018, Management of municipal development of Euroregion Beskydy in Poland and Czechia, in: Polish Journal of Management Studies, 18(1), p. 365-378.

28. United Nations, European Commission, International Monetary Fund, OECD, World Bank, 2003, Handbook of National Accounting. Integrated Environmental and Economic Accounting 2003, in: Studies in Methods, Series F, 61(1). (ST/ESA/STAT/ SER.F/61/Rev.1).

29. WCED, 1987, Our common future. Oxford University Press, Oxford, New York. 